\title{
Spoken Vocabulary to English Language Learners in K-12 Math and Science Classroom
}

\author{
Ai-Ling Kan \\ National Tsing Hua University
}

\begin{abstract}
Research has shown that academic written and spoken English have different language characteristics of lexical and grammatical features. Hence, the vocabulary developed from the academic written corpus may not fully capture the spoken language of educational lectures or classroom discussions. Notably, there are no studies related to spoken vocabulary use in the STEM classroom for English language learners (ELLs) from kindergarten to high school (K12).

Taking a corpus-driven approach, this study explored spoken vocabulary frequently and evenly distributed in teacher-student interactions in K-12 STEM classrooms. After verifying the overlap rate with the COCA oral corpus, the oral vocabulary is divided into K-12 math and science fields.

The results showed that high-frequency spoken vocabulary in STEM classrooms accounted for $72.66 \%$ of the COCA oral data in mathematics and $72.79 \%$ in science classes. Simultaneously, the coverage of spoken vocabulary and written words in STEM classrooms reached $92 \%$ in math classes, and $98 \%$ in science classes. This shows that STEM spoken vocabulary can provide ELLs with sufficient STEM vocabulary knowledge, and simultaneously, help ELLs enhance their understanding of teaching and discussion in STEM classrooms. This study suggests that spoken vocabulary can develop language fluency and also contribute to the development of reading skills.
\end{abstract}

Keywords: ELL; K-12; spoken corpus; spoken vocabulary; STEM vocabulary 